\title{
Molecular Biomarkers in Sinonasal Cancers: New Frontiers in Diagnosis and Treatment
}

\author{
Mario Turri-Zanoni $^{1,2}$ (1) $\cdot$ Giacomo Gravante ${ }^{1} \cdot$ Paolo Castelnuovo ${ }^{1,2}$
}

Accepted: 3 August 2021 / Published online: 20 January 2022

(c) The Author(s) 2022

\begin{abstract}
Purpose of Review Sinonasal tumors are rare and heterogeneous diseases which pose challenges in diagnosis and treatment. Despite significant progress made in surgical, oncological, and radiotherapy fields, their prognosis still remains poor. Therefore, alternative strategies should be studied in order to refine diagnosis and improve patient care.

Recent Findings In recent years, in-depth molecular studies have identified new biological markers, such as genetic abnormalities and epigenetic variations, which have allowed to refine diagnosis and predict prognosis. As a consequence, new histological entities have been described and specific subgroup stratifications within the well-known histotypes have been made possible. These discoveries have expanded indications for immunotherapy and targeted therapies in order to reduce tumor spread, thus representing a valuable implementation of standard treatments.

Summary Recent findings in molecular biology have paved the way for better understanding and managing such rare and aggressive tumors. Although further efforts need to be made in this direction, expectations are promising.
\end{abstract}

Keywords Biomarkers · Immunotherapy · Intestinal-type adenocarcinoma (ITAC) $\cdot$ INI-1 $\cdot$ Olfactory neuroblastoma Mucosal melanoma $\cdot$ Neuroendocrine carcinoma (SNEC) $\cdot$ Paranasal sinus cancer $\cdot$ PD-L1 $\cdot$ Sinonasal undifferentiated carcinoma (SNUC) $\cdot$ Targeted therapies

\section{Introduction}

Sinonasal tumors are rare and account for 3 to $5 \%$ of malignancies of the head and neck $(\mathrm{H} \& \mathrm{~N})$, and 0.2 to $0.8 \%$ of all tumors [1]. Diagnosis is often late and in the advanced stage due to tumor slow growth and non-specificity of the

This article is part of the Topical collection on Head and Neck Cancers

Mario Turri-Zanoni

tzmario@inwind.it

Giacomo Gravante

giacomo.gravante1@gmail.com

Paolo Castelnuovo

paolo.castelnuovo@me.com

1 Division of Otorhinolaryngology, Department of Biotechnology and Life Sciences, University of Insubria, Ospedale di Circolo e Fondazione Macchi, Via Guicciardini 9, 21100 Varese, Italy

2 Head and Neck Surgery \& Forensic Dissection Research Center (HNS\&FDRc), Department of Biotechnology and Life Sciences, University of Insubria, Varese, Italy symptoms which patients often neglect [2]. The average age of presentation is between 50 and 60 years with a higher prevalence in males [3]. A variety of histological cancer subtypes may arise in this region with different natural histories. Occupational hazards, genetic mutations, viral infections can be considered etiological agents in several tumors [4]. Most frequent malignancies of the sinonasal tract originate from the surface epithelium, in particular squamous cell carcinoma (SCC) and non-salivary-type adenocarcinoma (nsADC). The first is the most common tumor in the USA, typically originating from the maxillary sinus (60\%); the latter is the most common in Europe, arising in the ethmoid sinuses (85\%) and olfactory region (13\%) [1]. However, the sinonasal tract can be affected by a wide range of cancers, which differ markedly from each other in their clinical behavior. Despite recent advances in diagnosis and treatment, including minimally invasive endoscopic resection, neoadjuvant chemotherapy, and particle radiotherapy, the prognosis still remains dismal with a high recurrence rate and poor survival outcomes. For this reason, studies predominantly focused on the molecular fingerprint of each specific histotype, are paramount to engage new promising 
treatment strategies. Moreover, recent molecular studies enabled the discovery of new rare entities that require further efforts for understanding their natural history and choosing the appropriate therapeutic strategy.

\section{Squamous Cell Carcinoma}

SCC is a malignant epithelial tumor arising from the epithelium lining the nasal cavity and paranasal sinuses. The histologic subtypes of this tumor include keratinizing SCC (KSCC, $70 \%$ of cases, graded into well, moderately, and poorly differentiated), non-keratinizing SCC (NKSCC, 20\% of cases), and other less frequent variants, such as spindle cell SCC (10\% of cases) [5]. Exposure to chemical substances such as polycyclic aromatic hydrocarbons, glues, formaldehyde, chrome, nickel, and various compounds used in the textile industry has been associated with sinonasal SCC cancerogenesis [6, 7]. Chronic inflammation, supported by irritating substances, may have a role in converting normal respiratory epithelium into a squamous metaplasia and subsequent dysplasia, outlining the subsequent conversion in the so-called de novo SCC, associated with worse prognosis $[4,7]$. In addition, precursor lesions are represented by Schneiderian papillomas (exophytic, inverted, and oncocytic type), with potential of cancerization ranging from 2 to 27\% [7]. The role of the human papilloma virus (HPV) in sinonasal cancer is still debated [7]. HPV infection was identified in 16-19\% of KSCC and more consistently in NKSCC (50\%), with types 16 and 18 as the most common. In this context, NKSCC appears to be a distinct histopathologic and molecular disease from the keratinizing one. The first is characterized by high prevalence of high-risk HPV DNA, overexpression of p16 protein, high Ki-67 labeling index, and negative or low $\mathrm{p} 53$ reactivity; the latter is a tumor more frequently related to cigarette smoking, p53 anomalies, and low prevalence of HPV positivity. The presence of HPV is associated with a favorable outcome whereas TP53 mutation, detected in $30-75 \%$, is associated with worse prognosis [6]. Among NKSCC, a novel subtype with DEK-AFF2 fusion was recently reported, which showed an encouraging preliminary response to immune checkpoint inhibitors [8], and needs further efforts to investigate the mechanisms of that.

An association of the Epstein-Barr virus (EBV) and a high risk of metastatic and lymph node spread in sinonasal SCC has been found [9], but such findings should be further investigated. Epidermal growth factor receptor (EGFR) mutations, frequently observed in inverted papilloma (IP) and associated with low risk of SCC transformation [7], could represent a potential target in the prognosis and treatment of this cancer type [10]. In this regard, EGFR protein expression was associated with significantly shorter overall and disease-free survival in a series of 70 sinonasal SCC [11]. Moreover, Udager et al. found that the irreversible EGFR inhibitor, neratinib, strongly inhibited EGFR signaling and its downstream molecules Mek and Akt in a sinonasal SCC cell line [12]. Similarly, amplification of fibroblast growth factor receptors 1 (FGFR1), found in 20\% of SCC cases, represents a potential molecular target with FGFR-inhibitors $[4,10]$. Moreover, activation of PI3K/Akt/ mTOR pathway through PTEN loss and overexpression of Akt and mTOR observed in SCCs has been described as a potential option for targeted therapies in a preclinical setting $[13 \bullet \bullet]$. Finally, some tumoral cells may express the programmed death ligand-1 (PD-L1), which blocks the interaction between the programmed death-1 (PD-1) receptor and $\mathrm{T}$ lymphocytes, inhibiting their activation and suppressing the immune response. Although PD-L1 expression seems not to be directly correlated with prognosis, it can be used to select patients who may benefit from therapy with immune checkpoint inhibitors [14].

The potential prognostic role of selected biomarkers was also investigated in several studies. If on one side the P53 status plays a controversial role as prognosticator [15], on the other hand, the overexpression of TrkB and pS6 seems to be associated with more advanced grade and stage, with worse survival rates $[13 \bullet \bullet, 16]$.

\section{Intestinal-Type Adenocarcinoma}

Intestinal-type adenocarcinoma (ITAC) is the most common nsADC and occurs predominantly in the ethmoid sinuses (40-85\%) [5, 17]. Occupational exposure represents a key point in ITAC cancerogenesis, demonstrated in about $88 \%$ of cases [18]. The most important risk factor is exposure to wood dust, followed by products in the textile industry, leather dust, and formaldehyde; debated is the role nickel/ chromium compounds and asbestos [6, 19].

ITACs consist of the proliferation of dysplastic columnar cells with interspersed goblet cells, forming papillae and glands. Paneth cells and endocrine cells are also present in varying proportions. The spectrum of differentiation covers well-differentiated to poorly-differentiated tumors, stratified as papillary, colonic, and solid, or mixed, according to the Barnes classification [20]. A low percentage of cases shows abundant mucus, resulting in two different growth patterns: mucinous type and signet ring type [20].

Similarly, Kleinsasser and Schroeder divided ITAC into four subtypes: papillary-tubular cylinder cell, later graded from I to III, alveolar goblet, signet ring cell, and transitional, with the signet ring variant associated with the worst prognosis [21]. The differential diagnosis between ITAC and non-intestinal-type adenocarcinomas (n-ITAC) is made on morphologic grounds, supported by immunohistochemistry 
[19]. Metastatic gastrointestinal tumors, sharing many common features with ITACs, must be excluded by clinical and/ or imaging findings [22]. The genetic alterations in sinonasal ITAC partially overlap with those of colorectal adenocarcinoma. TP53 is the most frequently mutated gene (40-50\%), while APC, KRAS, and BRAF mutations are present in a minor subset. EGFR overexpression and gene amplification have been found in a subgroup; reports of overexpression of MET and nuclear $ß$-catenin expression were also described [23•]. A recent study based on next-generation sequencing (NGS) has identified recurrent somatic sequence variants in PIK3CA, APC, ATM, KRAS, NF1, LRP1B, BRCA1, ERBB3, CTNNB1, NOTCH2, and CDKN2A [24]. Genetic aberrations leading to loss of PTEN, CDH1, DCC, and APC often correlate with advanced stages and poor prognosis, as observed in colorectal cancers [25]. Several methylated genes were found in this cancer by Costales et al., and, in particular, TIMP3 methylation correlated with worse survival [26]. In addition, Tomasetti et al. suggested to investigate Mir126 as a circulating biomarker, which is expressed in malignant disease but not in benign lesions, in order to early detect malignant transformation and open the doors for potential therapeutic strategies [22, 27]. Recently, innovative treatments strategies based on the aforementioned molecular alterations are emerging for specific subgroups of patients. In detail, p53 protein status may be used to predict the response to chemotherapy. Induction chemotherapy according to the PFL (cisplatin, fluorouracil, and leucovorin) scheme seems to increase disease-free survival in the presence of a wild-type or a still-efficient $\mathrm{p} 53$ protein, even when encoded by a mutated TP53 gene, but ineffective in case of disabled p53 protein [28]. Additionally, mutational H-RAS profile, shown in $16 \%$ of ITAC, could fit into MAPK/ERK pathway inhibitors, alone or combined with inhibitors of the cyclin-dependent kinase-4/6 [19]. Since MET-activating mutation can be found in up to 64\% of ITACs, MET inhibitors represent another interesting treatment option [19]. As for SCC, the PD-L1 expression has been shown in 17\% of ITACs, supporting the potential for immune checkpoint inhibitors in selected cases of metastatic disease [14].

\section{Non-Intestinal-Type Adenocarcinoma}

n-ITAC is an utmost rare malignancy of the sinonasal tract which morphologically displays neither intestinal-type nor salivary-type adenocarcinoma's features. It is divided into low-grade and high-grade types. Degree of necrosis, mitotic activity, and cytologic atypia are the distinguishing characteristics between the two grades. As opposite to ITAC, wood dust exposure shows no significant association with n-ITAC tumorigenesis and the immunohistochemical panel demonstrates a respiratory-type profile $(\mathrm{CK} 20-, \mathrm{CK} 7+$, CDX2 - , and villin -), with CK7 consistently expressed
$[29,30]$. SATB2 has been recently identified as a potential diagnostic biomarker, capable of differentiating ITAC from n-ITAC with a high degree of specificity [31]. A molecular marker helpful in the diagnosis of these tumors may be also the OTX type 1 gene [32]. In line with this, Pirrone et al. demonstrated differential immunoreactivity of OTX1 and OTX2 between ITAC and n-ITAC types, where OTX1 is only absent from ITACs while OTX2 is absent from both [33]. Positivity for markers of seromucinous differentiation (DOG1, SOX10, and S-100) defines a subset of n-ITACs called sinonasal seromucinous adenocarcinomas [17]. n-ITAC includes also a rare subtype, namely the renal celllike adenocarcinoma, which is a low-grade glandular malignancy of the paranasal sinuses. Despite its morphologic mimicry of renal cell carcinoma, it demonstrates a seromucinous phenotype and is associated with a favorable prognosis and low recurrence rates after a free-margins surgical resection [34]. B-catenin and mismatch repair protein expression is wild type in high-grade n-ITACs [35]; while a subset of low-grade n-ITACs (with squamous morules) shows nuclear localization of $\beta$-catenin [36]. Overexpression of p53 may be seen [37]. In two studies reported by Andreasen et al., ETV6 rearrangement with NTRK3 (2 cases) and with RET (one case) could represent a promising target for therapy and a valid tool as a diagnostic biomarker $[38,39]$.

\section{Adenoid Cystic Carcinoma}

This is the most common salivary-type sinonasal tumor [40]. Its clinical behavior is deceptive since the tumor growth is slow but with a high propensity for perineural spread and bony local invasion, with extent through the skull base, cavernous sinus, and orbit; even systemic spread takes place especially to the lung, bone, and liver, while lymph node metastasis is less frequent [41•]. Three histological variants have been described: cribriform, tubular, and solid [5]. According to the Perzin/Szanto classification system, adenoid cystic carcinoma (ACC) is divided into three grades, with grade III defined by more than $30 \%$ of solid components and associated with worse outcomes [42, 43]. Focusing on molecular subtypes and based on dominant cell type, ACC may show an epithelial-dominant trait (E-ACC) or a myoepithelial-dominant trait (M-ACC), enabling the identification of novel potential therapeutic targets and biomarkers [44]. Moreover, M-ACC is correlated with better prognosis [45]. Genes EN1, DLX6, and OTX1 represent potential drivers and therapeutic targets for ACC [44]. Specific gene rearrangements have been described, in particular MYB-NFIB fusion, found in $50-60 \%$ of cases, resulting from a $t(6,9)$ translocation which fuses the MYB proto-oncogene on chromosome $6 \mathrm{q}$ to the NFIB gene on chromosome 9p; this leads to an increased expression of the protein Myb, involved in 
the tumoral growth and associated with a more aggressive clinical course. Targeted therapy of transcription factors remains currently a major challenge $[46,47]$. Moreover, ACC may express NOTCH1 mutations which characterize a poor-prognosis disease, with solid histological phenotype, high tendency in liver and bone spread, and potential responsiveness to Notch1 inhibitors [48]. EGFR and c-Kit genetic abnormalities have been observed in sporadic cases, even if specific therapies against these targets have not resulted in significant clinical responses $[49,50]$. Other activating mutations may involve the vascular endothelial growth factor (VEGF) and fibroblast growth factor receptor 1 (FGFR1), supporting the need for further exploration of targeting inhibitors in this field [39]. Finally, matrix metalloproteinases (MMPs) seem to have a role in promoting ACC local and distant spread, due to their disruptive capacity on extracellular and pericellular components; in particular, immunoexpression of MMP-7 and MMP-25 is associated with better survival while high tumoral expression of MMP-9 and MMP-15 is associated with poorer survival, advanced stage, and regional recurrences [51].

\section{HPV-Related Multiphenotypic Sinonasal Carcinoma}

HPV-related multiphenotypic sinonasal carcinoma (HPVMSC) is morphologically similar to ACC, particularly to its solid variant, but not presenting MYB, MYBL1, or NFIB fusion genes $[52,53]$. The salivary gland nature of this tumor is further supported by myoepithelial cells positivity for cytokeratin, S100, actin, calponin, p63, and ductal cells positivity for CD117 and CK7. Expression of SOX10 and LEF-1 is typical in these tumors [54-57]. The presence of focal squamous differentiation within the tumor is characteristic of HPV-MSC [55]. High-risk HPV genotypes infection such as type 33, the most common, but also types 35,52 , and 56 , strongly support the diagnosis $[53,58]$. Although HPVMSC has a high-grade histological appearance, it behaves indolent with frequent local relapses and only rare systemic metastases, and therefore, surgery followed by irradiation represents the standard of care [53]. Innovative biological treatment options deserve future studies.

\section{Olfactory Neuroblastoma}

Olfactory neuroblastoma (ONB) is a malignant tumor typically arising from the olfactory neuroepithelium in the upper nasal cavity. It commonly involves the ethmoid complex, anterior skull base, and orbit, locally, while regional spread to neck nodes and systemic dissemination to brain, leptomeninges, lung, and bones may occur with a frequency ranging from 10 to $15 \%$. Cases of ONBs with a syndrome of inappropriate antidiuretic hormone secretion (SIADH) have also been described in the literature [59,60]. Differential diagnosis is challenging, especially in differentiating ONB from other small round blue cells tumors, such as mucosal melanoma, rhabdomyosarcoma, sinonasal undifferentiated carcinoma (SNUC), NUT carcinoma, sinonasal neuroendocrine carcinoma (SNEC), Ewing sarcoma, and pituitary adenoma [61]. The Hyams grading system is widely accepted to stratify ONB cases in four grades according to an increased level of mitotic activity, nuclear polymorphism, Wright and Flexner-Wintersteiner rosettes, subverted architecture, necrosis, and decreased amount of fibrillary matrix [62]. Several studies supported the crucial role of Hyams grade in treatment planning, given its statistically significant association with overall prognosis and recurrence rates [63, 64]. Hyams grade III and IV ONB can be considered poorly differentiated cancers, sharing common biological alterations with SNUC and poorly differentiated SNEC, thus making difficult a proper differential diagnosis. In addition, such cancers share also a high chemo-radiosensitive behavior, so that they may benefit from different protocols of neoadjuvant chemotherapy, including the cisplatin/etoposide scheme, which might be used to select responders who can be treated with exclusive chemoradiation with slightly better survival rates $[62,64]$.

The immunohistochemical panel includes consistent and diffuse staining for neuronspecific enolase, chromogranin A, synaptophysin, CD56, and S100 typically localized in sustentacular cells. As opposed, CK-AE1/AE3, CK-8/18, and TTF-1 staining are usually negative. However, ONBs are a heterogeneous group of tumors and the expression of cytokeratin and chromogranin A and the mutational status of IDH2 as well as DNA methylation patterns may greatly aid in the precise classification of ONB subtypes with different biological behavior [65]. Although p53 positivity does not seem to correlate to survival, the Ki67 index can be variable (2-50\%), and when elevated, it is associated with an increased risk of recurrence and poorer outcomes $[64,66]$. Micheloni et al. described the OTX type 2 gene (OTX2) as a useful molecular marker for the diagnosis of ONB [32]. Molecular-based subtype classification has been proposed for ONBs, dividing them into neural type and basal type, with the latter characterized by worse prognosis and higher intratumoral-infiltrating lymphocytes, providing thus a rationale for the use of immune checkpoint inhibitors in this setting [67]. Moreover, ONB can express somatostatin receptor (SSTR), in particular SSTR-2 (75\%) and, less often, SSTR-5 (7.5\%), both showing the highest affinity with somatostatin analogs among all SSTR families. Thereby, somatostatin analogs can be used for diagnosis, especially in case of metastatic disease, using octreotide (111In-pentetreotide) SPECT/CT and, more recently, 
Gallium-68 (68 Ga) PET/CT with restricted time of image acquisition, better resolution, and lower radiation dose [68, 69]. Treatment protocols with somatostatin analogs are currently under intensive investigations, as well, especially in cases of recurrences not amenable for surgery and further irradiation [69]. Numerous chromosomal aberrations have been reported in the literature proving that gains are more frequent than losses and associated with advanced-stage tumors [66]. Moreover, genomic alteration in PI3K/mTOR signaling pathway and CDK-dependent cell cycle regulation may be involved in ONB pathogenesis, as well as CCND1 amplification, FGFR3 amplifications, and DMD gene deletions, all of them potentially opening new horizons for targeted therapy, which should be further investigated in future studies [70-73]. Topcagic et al. identified protein biomarkers potentially associated with response or resistance to classic chemotherapy drugs, in particular low ERCC1 (cisplatin sensitivity), high TOPO1 (irinotecan sensitivity), high TUBB3 (vincristine resistance), and high MRP1 (multidrug resistance) [74]. In addition, the authors demonstrated aberrations in the targetable $\mathrm{Wnt} / \beta$-catenin signaling pathway as well as cell cycle master regulator TP53, which may confer sensitivity to WEE kinase inhibitors. Positivity for PD-L1 in ONB tumor cells is variously described in the literature and it might open the door for studies assessing the efficacy of immunotherapy (nivolumab, pembrolizumab) in this disease $[22,74]$.

\section{Mucosal Melanoma}

Sinonasal mucosal melanoma (MM) is the most aggressive sinonasal tumor, currently characterized by early recurrence and high dissemination rates regardless of the treatment adopted. Free-margins surgery is the mainstay of treatment since it is generally considered a radio-resistant cancer [5]. A High pigmentation rate may help diagnosis, but when lacking, immunohistochemistry becomes paramount: S100 protein and SOX10 are usually strongly positive, while other melanocytic markers (HMB45, tyrosinase, melan A, MITF) have variable expression [61]. The well-known mutated genes involved in cutaneous melanoma cancerogenesis, unfortunately, have only a marginal role in MM, reporting variable frequencies of mutations, as follows: $7-30 \%$ in NRAS, $0-25 \%$ in c-KIT, $8-11 \%$ in TERT, $3-10 \%$ in BRAF (only in one study, 36\%), 7\% in SF3B1, and KRAS mutations reported only in anecdotic cases [23•]. Globally, the infrequent rate of BRAF V600E mutation observed in MM limits the efficacy of BRAF inhibitors, largely used in cutaneous melanoma, while the higher NRAS and c-KIT mutations rates make them potentially susceptible to NRAS and c-Kit target therapies [5, 22, 61, 75]. In this regard, sorafenib and imatinib molecules have been used in cases harboring specific mutations but without significant improvement in overall survival rates [76]. However, this lack of improvement may be explained by the fact that this treatment was generally given to those with end-stage, disseminated disease. Other potential therapeutic strategies may involve loss of PTEN and p16/INK4a, which may indicate activation of PI3K/Akt/mTOR and RAS/MAPK pathways [75]. However, genetic alterations have been found only in a small fraction of cases, thus supporting the urgent need for alternative treatment strategies. Recently, immunotherapy has shown promising results in selected cases, both in neoadjuvant and adjuvant settings, especially in terms of decreased systemic spread of disease. Hur et al. reported the use of ipilimumab, a monoclonal antibody targeting CTLA-4, in a cohort of metastatic MM, obtaining a $12.5 \%$ response rate, improved up to $23 \%$ when combined with the anti-PD1 therapy, nivolumab [77]. The concept of sequential immune checkpoint blockade with two inhibitors, such as anti-PD1 and anti-CTLA-4, merits further study to determine which patients are most likely to benefit, especially due to the potential escape oncogenic mechanisms intrinsic to $\mathrm{MM}$ biologic nature. $\mathrm{MM}$ is able to switch its oncogenic driver during a targeted therapy, in order to survive and continue its tumoral progression. Drug sensitivity may be regained upon treatment discontinuation but a permanent resistance to therapy is often detected. Thereby, longitudinal molecular studies and further deciphering in the molecular and immunological frame of MM are currently ongoing worldwide in order to better understand cellular plasticity and drive the treatment strategies [78].

\section{Sinonasal Undifferentiated Carcinoma}

SNUC is a highly aggressive carcinoma lacking glandular or squamous features with great local aggressivity and tendency to metastasize [1]. In general, SNUC presents high chemosensitivity to cisplatin-based regimen and the partial or complete response to induction chemotherapy (IC) is considered a favorable prognostic factor, guiding the treatment choice toward definitive chemoradiation [79, 80]. Conversely, in patients who do not achieve a favorable response to IC, surgery, when feasible, seems to provide a better chance of disease control and improved survival [79].

SNUC is generally regarded as a diagnosis of exclusion given the complexities in its definition and misdiagnosis is frequent. The immunohistochemical panel stains positively for epithelial markers (AE1/AE3, CK7, CAM5.2, EMA), p16, CD117, and focal p63 and negatively for CK5/6, p40, CEA, EBER, CD34, desmin, S100 protein, and calretinin. Neuroendocrine markers (NSE, synaptophysin, chromogranin, CD56) may be present $[61,81]$. CLCA2 is shown to have reduced expression in SNUC compared with SCC, 
leading to improved proliferation, migration, invasion, and epithelial-mesenchymal transition. Thus, restoration of CLCA2 function might be a promising therapy in the future [22, 82-84]. Recently, a SNUC subtype characterized by mutations of the metabolic enzymes IDH2 involved in the Krebs cycle has been described [85]. Jo et al. found IDH2 R172X mutations in 55\% of SNUCs [86]; other mutations in the same codon (R172S, R172T, and R172M) have been described, with frequency up to $82 \%$ of cases [87]. Thus, patients presenting with IDH 2 mutations may benefit from therapy with targeted IDH inhibitors enasidenib and ivosidenib, recently approved by FDA [87]. Since the mutation almost always occurs at the same codon, Dogan et al. have determined the utility of the 11C8B1 monoclonal antibody as a surrogate marker for this mutation in order to easily identify IDH2-mutant SNUC [88]. Remarkably, Dogan et al. found an improved disease-free survival and reduced lung metastasis in IDH-mutant SNUC. Interestingly, IDH2 mutations may be present even in large-cell neuroendocrine carcinomas, sharing with IDH2-mutant SNUC also similar cancer signaling pathways. Moreover, IDH2-mutated carcinomas seem to be characterized by hypermethylation and upregulation of the repressive H3K27 epigenetic mark, opening the door for a DNA methylation-based classification of SNUC [88].

\section{SWI/SNF Complex-Deficient Sinonasal Carcinoma}

The loss of SMARCB1 (INI1) protein expression, which is a member of the chromatin-remodeling SWI/SNF complex located at 22q11.2, can be identified in selected cases of poorly or undifferentiated sinonasal epithelial cancers, referred to as SMARCB1-deficient sinonasal carcinomas. This loss represents a negative prognostic factor, associated with a high propensity for systemic spread and reduced overall survival, so that some authors proposed to define such cancers as distinct entities in their own right [85, 89]. Histologically, undifferentiated basaloid morphology, often with rhabdoid or plasmacytoid features, is recognizable. The immunohistochemical profile displays the expression of pancytokeratin (AE1/AE3), CK5, p63, CK7, and neuroendocrine markers [85, 87]. Coexisting genetic alterations reported by Dogan et al. included loss of NF2 and CHEK2 (50\%), chromosome 7 gain (25\%), and TP53 V157F, CDKN2A W110, and CTNNB1 S45F mutations [90]. The DNA methylation analysis described by Laco et al. found a significantly higher methylation level of the RASSF1 gene [91]. A novel entity is represented by SMARCB1-deficient sinonasal adenocarcinoma, with only few cases described in the literature so far [92]. It displays predominantly an oncocytoid/plasmacytoid cell pattern with prominent gland formation; patterns of yolk sac tumors are seen up in onequarter of cases and may rarely be the predominant pattern. It may be misdiagnoses with high-grade intestinal or nonintestinal adenocarcinoma, myoepithelial carcinoma, or even yolk sac tumor or metastatic hepatocellular carcinoma [92].

SMARCA4 (BRG1)-deficient sinonasal carcinoma represents another uncommon tumor subtype where the SWI/SNF chromatin-remodeling complex is aberrated. Very few cases have been described in the literature so far, which were morphologically and clinically similar to INI1-deficient sinonasal cancers. As opposed to SMARCB1-deficient tumor, it shares more overlapping features with SNUC and poorly differentiated neuroendocrine carcinomas [85, 87]. Loss of additional SWI/SNF subunits, mainly the SMARCA2, is utmost rare and reported in a few cases [93, 94].

The identification of SWI/SNF complex subunits as key players in sinonasal cancer prompts intrigue in the potential efficacy of novel therapies. Targeted therapies with enhancer of zeste homolog 2 (EZH2) and cyclin-dependent kinase 4/6 (CDK4/6) inhibitors may emerge as potential options for treating tumors with SMARCA4 inactivation $[95,96]$. In addition, a recent study demonstrated the susceptibility of SMARC4A-deficient ovarian and lung cancer models to bromodomain inhibitors [97]. Whether this applies in sinonasal carcinoma warrants investigation.

\section{NUT Carcinoma}

NUT carcinoma is a highly aggressive carcinoma defined by $t(15 ; 19)$ translocation, supported by the fusion of the NUT (NUTM1) gene on chromosome 15q14 with BRD4 on chromosome 19p13. Rarely, NUT-BRD3 and NUT-NSD3 are involved in this translocation [61,87]. Patients with nonBRD4-NUTM1 fusions (BRD3- or NSD3-NUTM1, median overall survival, 36.5 months) have significantly better survival than those with BRD4-NUTM1 fusions (median overall survival, 10 months), independently of metastatic disease extent at presentation [98]. Morphologically, it contains differentiated/undifferentiated cells with variable necrosis and numerous mitotic figures. More than $50 \%$ of nuclear labeling with a monoclonal antibody targeting NUT mutation is required for diagnosis. Bromodomain (NUT) inhibitors might represent a promising targeted treatment for such tumors presenting with a very poor prognosis to date [61, 87].

\section{Teratocarcinosarcoma}

Teratocarcinosarcoma (TCS) is a high-grade sinonasal malignancy defined histologically by features of malignant teratoma, carcinoma, and sarcoma with fetal-like clear cell 
appearance, and a variety of mesenchymal elements [95]. Most likely histogenesis theory is from somatic pluripotent stem cells in the olfactory membrane [95]. Vranic et al. reported a case with trisomy $12 \mathrm{p}$, a well-known cytogenetic abnormality occurring in the majority of malignant germ cell tumors [99]. NGS reported activating CTNNB1 mutation in a single case of TCS [100]. Rooper et al., interestingly, found a loss of SMARCA4 expression in 18 cases of TCS (82\%) and variable positivity for Claudin-4 [95]. These results provide important information about the emerging role of SMARCA4 in sinonasal cancers and particularly suggest that TCS is on a spectrum with SMARCA4-deficient sinonasal carcinomas and could benefit from similar novel targeted therapies [95]. Moreover, the potential involvement of $\mathrm{Wnt} / \beta$-catenin and PI3K/AKT/mTOR pathways could support specific treatments for this tumor $[100,101]$.

\section{Sinonasal Neuroendocrine Carcinoma}

SNEC is a rare poorly differentiated carcinoma with neuroendocrine differentiation, characterized by a dismal prognosis and a high tendency to produce systemic metastasis [61]. It can be divided into small- and large-cell carcinomas, with different biological profiles and clinical courses [102••]. The immunohistochemical profile includes positivity for pancytokeratin (AE1/AE3), CK8/18, neuroendocrine markers (synaptophysin, chromogranin, NSE, CD56; at least one). The Ki67 mitotic index is usually more than $20 \%$. Rooper et al. studied the status of insulinoma-associated protein 1 (INSM1) in H\&N neuroendocrine carcinomas, finding a consistent positivity in all cases, thus supporting the role of INSM1 as a diagnostic biomarker for SNECs [103]. SNEC may benefit from induction chemotherapy followed by concurrent chemoradiation; surgery can be performed in nonresponsive cases or as a salvage treatment [61, 64]. From a molecular viewpoint, Kovarikova et al. found an MiR-21 upregulation in several cancers, including SNEC, which seems to be associated with poor prognosis; however, further investigations are required in this direction [104]. Dogan et al., using the hierarchical clustering, described a cluster of IDH2-mutated carcinomas including not only SNUC but even large-cell SNEC, which shared a largely similar epigenetic signature. On the other hand, small-cell SNECs and SMARCB1-deficient sinonasal carcinomas seem to be molecularly distinct from IDH2-mutated carcinomas, as supported by the distribution of ARID1A mutations, which were common in small-cell SNEC but not among IDH2mutant cancers [88]. Lastly, based on the presence of neuroendocrine and nonneuroendocrine tumoral components, a new entity has been recently described, namely the mixed neuroendocrine-nonneuroendocrine neoplasm (MiNEN) [64]. It is characterized by the presence of at least $30 \%$ of the neuroendocrine component within a nonneuroendocrine cancer (e.g., ITAC, SCC), and unfortunately, it bears a very poor prognosis $[64,105]$. Due to the extreme rarity of this disease, no studies are available concerning potential biomarkers for improved diagnosis, prognosis, and treatment.

\section{Chondrosarcoma}

Chondrosarcoma of the sinonasal tract is an uncommon tumor arising from hyaline cartilage. They are divided into low, intermediate, and high grade, with the former showing indolent/slow growth [5]. Mesenchymal chondrosarcoma represents an aggressive high-grade variant with a biphasic component of undifferentiated small blue round cells with islands of well-differentiated hyaline cartilage. The paucity of cartilage may result in frequent misdiagnosis. The immunohistochemical profile includes positivity to CD99, CD56, NSE, GFAP, desmin, and synaptophysin, whereas negativity to keratins and $\mathrm{S} 100$ protein. SOX9, a regulator of chondrogenesis, is the most helpful marker because it is non-reactive in the other small round blue cell tumors [61, 106]. Moreover, HEY1-NCOA2 fusions are held by $80 \%$ of tumors, providing another valid diagnostic tool [107]. IDH1/2 mutations were associated with longer disease-free survival and open to therapeutic targeted strategies with IDH-inhibitor therapy [90].

\section{Undifferentiated Small Round Cell Sarcomas}

Ewing Sarcoma (ES) is a primitive small round cell sarcoma defined by fusions involving members of the FET (predominantly EWSRI or FUS) and ETS (most commonly including FLII, ERG, ETVI, ETV4, or FEV) gene families. The translocation of the EWSR 1 gene, located on $22 \mathrm{q} 12$, and the FLI-1 gene, located on 11q24, resulting in a $t(22 ; 11)$, is the most frequently observed. Translocation variants are detected in $10-15 \%$ of cases [61, 108]. It occurs mainly in young male patients and is classified in two entities: skeletal form, typically occurring in the long bones of the extremities, and extraskeletal form, such as those involving paranasal sinuses [109]. Immunohistochemical positivity to neural markers (NSE, S100, synaptophysin, chromogranin) is often reported. A combination of CD99, strongly expressed, and NKX2.2, found in around 95\% of ES, may improve the diagnosis $[110,111]$. Multidisciplinary treatment is required, but local recurrences and distant metastases are usually soon developed, within 2 years after the initial presentation. Moreover, p53 mutation has been reported as a poor prognosticator [61]. Adamantinoma-like Ewing sarcoma (ALES) is a rare variant of ES defined 
Table 1 Summary of molecular biomarkers in sinonasal cancers

\begin{tabular}{|c|c|c|}
\hline Tumor histotype & Immunohistochemical panel & Molecular profile \\
\hline SCC & $\begin{array}{l}\text { Positivity for pancytokeratins, CK5/6, p63, p } 40 \text {, EMA } \\
\text { TrkB and pS6 are negative prognostic biomarkers }\end{array}$ & $\begin{array}{l}\text { TP53, EGFR, FGFR, PD-L1, PI3K/Akt/mTOR, HPV- } \\
\text { DNA, DEK-AFF2 fusion }\end{array}$ \\
\hline ITAC & $\begin{array}{l}\text { Positivity for pancytokeratins, CK20, CDX2, villin, } \\
\text { MUC2 } \\
\text { Negativity for CK7 }\end{array}$ & $\begin{array}{l}\text { TP53, EGFR, MET, KRAS, BRAF, PD-L1, PTEN, } \\
\text { CDH1, DCC, APC, CTNNB1, TIMP3, PIK3CA, ATM, } \\
\text { NF1, LRP1B, BRCA1, ERBB3, NOTCH2, CDKN2A, } \\
\text { Mir126 }\end{array}$ \\
\hline n-ITAC & $\begin{array}{l}\text { Positivity for pancytokeratins, CK7, CDX2, MUC2 } \\
\text { Negativity for CK20, villin }\end{array}$ & OTX1, ETV6-NTRK3 fusion, ETV6-RET fusion \\
\hline $\mathrm{ACC}$ & $\begin{array}{l}\text { Positivity for CD117 (inner epithelial cells) and p63, } \\
\text { SMA (peripheral myoepithelial cells). MMP-7,-25 } \\
\text { (better prognosis) and MMP-9, }-15 \text { (poor prognosis) }\end{array}$ & $\begin{array}{l}\text { MYB-NFIB fusion t(6,9), KIT, EGFR, FGFR1, VEGF, } \\
\text { NOTCH1, EN1, DLX6, OTX1 }\end{array}$ \\
\hline HPV-MSC & $\begin{array}{l}\text { Positivity for cytokeratin, S100, actin, calponin, p63 } \\
\text { (myoepithelial cells) and CD117, CK7 (ductal cells). } \\
\text { SOX10, LEF-1 }\end{array}$ & Negativity for MYB, MYBL1, or NFIB fusion genes \\
\hline ONB & $\begin{array}{l}\text { Positivity for NSE, S100, chromogranin A, synaptophy- } \\
\text { sin, CD56 } \\
\text { Negativity for pancytokeratin, CK-8/18, TTF-1 }\end{array}$ & $\begin{array}{l}\text { OTX2, SSTR2 (75\%), SSTR5 (7,5\%), PI3K/mTOR, } \\
\text { CCND1, FGFR3, DMD, PD-L1, methylation status }\end{array}$ \\
\hline MM & $\begin{array}{l}\text { Positivity for S100, SOX10, HMB45, tyrosinase, melan } \\
\text { A, MITF }\end{array}$ & $\begin{array}{l}\text { NRAS (G12 hot-sport mutation), KIT, TERT, BRAF, } \\
\text { SF3B1, KRAS, PTEN, p16/INK4a, PD-L1 }\end{array}$ \\
\hline SNUC & $\begin{array}{l}\text { Positivity for pancytokeratin, CK7, OSCAR, CAM5.2, } \\
\text { EMA, p16, CD117, p63 } \\
\text { Variable expression of neuroendocrine markers } \\
\text { Negativity for CK5/6, p40, CEA, EBER, CD34, desmin, } \\
\text { S100, calretinin }\end{array}$ & Particular subtype: IDH-mutant SNUC \\
\hline $\begin{array}{l}\text { SWI/SNF complex- } \\
\text { deficient sinonasal } \\
\text { carcinoma }\end{array}$ & Positivity for pancytokeratin, neuroendocrine markers & SMARCB1, SMARCA4, SMARCA2 \\
\hline NUT carcinoma & Positivity for pancytokeratin, CK5/6, p63, p40 & $\begin{array}{l}\text { NUT-BRD4 fusion } \mathrm{t}(15,19) \text {, rarely NUT-BRD3 and NUT- } \\
\text { NSD3 }\end{array}$ \\
\hline Teratocarcinosarcoma & $\begin{array}{l}\text { Positivity for epithelial, mesenchymal, and neuroepithe- } \\
\text { lial markers } \\
\text { Negativity for PLAP, alpha-fetoprotein, hCG, and CD30 }\end{array}$ & $\begin{array}{l}\text { Trisomy 12p, CTNNB1, SMARCA4, CLDN4, Wnt/ק- } \\
\text { catenin, PI3K/AKT/mTOR }\end{array}$ \\
\hline SNEC & $\begin{array}{l}\text { Positivity for pancytokeratin, CK8/18, neuroendocrine } \\
\text { markers (synaptophysin, chromogranin, NSE, CD56- } \\
\text { at least one) } \\
\text { Negativity for S100, TTF-1 }\end{array}$ & $\begin{array}{l}\text { INSM1, Mir21, IDH2-mutations (large-cell SNEC), } \\
\text { ARID1A-mutations (small-cell SNEC) }\end{array}$ \\
\hline Chondrosarcoma & $\begin{array}{l}\text { Positivity for CD99, CD56, NSE, GFAP, desmin, synap- } \\
\text { tophysin, SOX9 } \\
\text { Negativity for keratins, S100 }\end{array}$ & HEY1-NCOA2 fusion, IDH1/2 mutations \\
\hline Ewing sarcoma & $\begin{array}{l}\text { Positivity for CD99, NKX2.2, NSE, S100, synaptophy- } \\
\text { sin, chromogranin }\end{array}$ & FET-ETS fusion, typically EWSR1-FLI1 fusion $t(22 ; 11)$ \\
\hline TFCP2-RMS & Positivity for desmin, myogenin, myosin, myoglobin & TFCP2-EWSR-1/FUS fusion \\
\hline BSNS & $\begin{array}{l}\text { Positivity for S100, SMA, calponin, b-catenin } \\
\text { Variable expression for desmin, myogenin, factor XIIIa }\end{array}$ & PAX3-MAML3 fusion $t(2 ; 4)$ \\
\hline Glomangiopericytoma & $\begin{array}{l}\text { Positivity for SMA, vimentin, nuclear } \beta \text {-catenin } \\
\text { Negativity for pancytokeratin, Bcl-2, CD34, CD99, } \\
\text { CD117, S100, STAT6 }\end{array}$ & CTNNB1, LEF1 \\
\hline
\end{tabular}

Abbreviations: $S C C$, squamous cell carcinoma; ITAC, intestinal-type adenocarcinoma; $n$-ITAC, non-intestinal-type adenocarcinoma; $A C C$, adenoid cystic carcinoma; HPV-MSC, HPV-related multiphenotypic sinonasal carcinoma; $O N B$, olfactory neuroblastoma; $M M$, mucosal melanoma; $S N U C$, sinonasal undifferentiated carcinoma; SNEC, sinonasal neuroendocrine carcinoma; TFCP2-RMS, rhabdomyosarcoma with TFCP2 rearrangement; $B S N S$, biphenotypic sinonasal sarcoma

by complex epithelial differentiation, with an expression of pancytokeratin, CD99, p40, and synaptophysin and frequent keratin pearl formation [112].
Rhabdomyosarcoma with TFCP2 rearrangement (TFCP2-RMS) is a high-grade rhabdomyosarcoma, characterized by a fusion of TFCP 2 to EWSR-1 or FUS. Most 
TFCP2-RMS arise in bone, less frequently in soft tissue. There is a striking predilection for craniofacial bones, in decreasing order of frequency the mandible, maxilla, and skull bones, from where TFCP2-RMS commonly infiltrates into the soft tissues of the mouth, nose, and neck. They are associated with a poor prognosis, including regional and distant spread, with high rates of diseaserelated death. Their association with ALK overexpression might represent a therapeutic target $[113,114]$.

\section{Biphenotypic Sinonasal Sarcoma}

Biphenotypic sinonasal sarcoma (BSNS) is a low-grade sinonasal sarcoma with neural and myogenic differentiation. It demonstrates a slowly progressive growth and encouraging overall survival outcomes, with possible local recurrences reported in a percentage up to $32 \%$ of cases [115-117]. Histologically, BSNS is characterized by "herringbone" fascicular pattern, "staghorn" vessels, and consistent immunohistochemical positivity for S100, smooth muscle actin (SMA), calponin, and b-catenin. Moreover, it can also show a variable expression of desmin, myogenin, and factor XIIIa, while it is negative for cytokeratin and SOX10 [118]. Crucial for diagnosis is the chromosomal translocation $t(2 ; 4)$ (q35; $\mathrm{q} 31.1$ ), resulting in a PAX3-MAML3 fusion protein, which is a potent transcriptional activator of PAX3 response elements [119]. Alternative PAX3 partners include FOXO1, NCOA1, NCOA2, and WWTR1 [117].

\section{Glomangiopericytoma}

Glomangiopericytoma (GPC), also named sinonasal hemangiopericytoma, is a rare mesenchymal tumor unique to the sinonasal tract and characterized by prominent perivascular growth. GPC shows epithelioid cells in a perivascular pattern with frequent perivascular hyalinization. It stains positively for cytoplasmic SMA, Vimentin, and nuclear $\beta$-catenin in 80-100\% cases [120]. GPC expresses lymphoid enhancerbinding factor 1 (LEF1), a protein downstream from $\beta$-catenin. Moreover, mutation analysis displays CTNNB1 exon 3 mutations, specifically in the GSK3beta region, with the activation of the Wnt signaling pathway $[121,122]$.

\section{Conclusions}

Sinonasal cancers are rare and extremely heterogeneous tumors. Given their aggressive behavior, novel diagnostic, prognostic, and therapeutic biomarkers are strongly required. Genetic and epigenetic changes described so far, as summarized in Table 1, are promising but it is still difficult to utilize all of them as biomarkers in daily clinical practice. Therefore, large multi-center studies are necessary to further validate these findings, in order to build a comprehensive model of carcinogenesis for each sinonasal cancer subtype. This will finally support the translation of personalized cancer medicine into the clinical management of sinonasal cancers, which will surely lead to improved survival for this challenging group of cancers.

\section{Declarations}

Conflict of Interest The authors declare no competing interests.

Human and Animal Rights and Informed Consent This article does not contain any studies with human or animal subjects performed by any of the authors.

Consent for Publication Publication consent was obtained from all authors.

Open Access This article is licensed under a Creative Commons Attribution 4.0 International License, which permits use, sharing, adaptation, distribution and reproduction in any medium or format, as long as you give appropriate credit to the original author(s) and the source, provide a link to the Creative Commons licence, and indicate if changes were made. The images or other third party material in this article are included in the article's Creative Commons licence, unless indicated otherwise in a credit line to the material. If material is not included in the article's Creative Commons licence and your intended use is not permitted by statutory regulation or exceeds the permitted use, you will need to obtain permission directly from the copyright holder. To view a copy of this licence, visit http://creativecommons.org/licenses/by/4.0/.

\section{References}

Papers of particular interest, published recently, have been highlighted as:

- Of importance

$\bullet$ Of major importance

1. Castelnuovo P, Turri-Zanoni M, Battaglia P, et al. Sinonasal malignancies of anterior skull base: histology-driven treatment strategies. Otolaryngol Clin North Am. 2016;49(1):183-200. https://doi.org/10.1016/j.otc.2015.09.012.

2. Jégoux F, Métreau A, Louvel G, Bedfert C. Paranasal sinus cancer. Eur Ann Otorhinolaryngol Head Neck Dis. 2013;130(6):327-35. https://doi.org/10.1016/j.anorl.2012.07.007.

3. Youlden DR, Cramb SM, Peters S, et al. International comparisons of the incidence and mortality of sinonasal cancer. Cancer Epidemiol. 2013;37(6):770-9. https://doi.org/10.1016/j.canep.2013.09.014.

4. Llorente JL, López F, Suárez C, Hermsen MA. Sinonasal carcinoma: clinical, pathological, genetic and therapeutic advances. Nat Rev Clin Oncol. 2014;11(8):460-72. https:// doi.org/10.1038/nrclinonc.2014.97. 
5. López F, Lund VJ, Suárez C, et al. The impact of histologic phenotype in the treatment of sinonasal cancer. Adv Ther. 2017;34(10):2181-98. https://doi.org/10.1007/ s12325-017-0605-9.

6. Franchi A, Miligi L, Palomba A, et al. Sinonasal carcinomas: recent advances in molecular and phenotypic characterization and their clinical implications. Crit Rev Oncol Hematol. 2011;79(3):265-77. https://doi.org/10.1016/j.critrevonc.2010.08.002.

7. Sahnane N, Ottini G, Turri-Zanoni M, et al. Comprehensive analysis of HPV infection, EGFR exon 20 mutations and LINE1 hypomethylation as risk factors for malignant transformation of sinonasal-inverted papilloma to squamous cell carcinoma. Int $\mathbf{J}$ Cancer. 2019;144(6):1313-20. https://doi.org/10.1002/ijc.31971.

8. Rooper LM, Agaimy A, Dickson BC, et al. DEK-AFF2 Carcinoma of the sinonasal region and skull base: detailed clinicopathologic characterization of a distinctive entity. Am J Surg Pathol. 2021;45(12):1682-93. https://doi.org/10.1097/PAS. 0000000000001741 .

9. Doescher J, Piontek G, Wirth M, et al. Epstein-Barr virus infection is strictly associated with the metastatic spread of sinonasal squamous-cell carcinomas. Oral Oncol. 2015;51(10):929-34. https://doi.org/10.1016/j.oraloncology.2015.07.008.

10. Re M, Gioacchini FM, Bajraktari A, et al. Malignant transformation of sinonasal inverted papilloma and related genetic alterations: a systematic review. Eur Arch Otorhinolaryngol. 2017;274(8):2991-3000. https://doi.org/10.1007/ s00405-017-4571-2.

11. Takahashi Y, Bell D, Agarwal G, et al. Comprehensive assessment of prognostic markers for sinonasal squamous cell carcinoma. Head Neck. 2014;36(8):1094-102. https://doi.org/10. 1002/hed.23423.

12. Udager AM, Rolland DCM, McHugh JB, et al. High-Frequency Targetable EGFR mutations in sinonasal squamous cell carcinomas arising from inverted sinonasal papilloma. Cancer Res. 2015;75(13):2600-6. https://doi.org/10.1158/0008-5472. CAN-15-0340.

13••. Muñoz-Cordero MG, López F, García-Inclán C, et al. Predictive value of EGFR-PI3K-pAKT-mTOR-pS6 pathway in sinonasal squamous cell carcinomas. Acta Otorrinolaringol Esp (Engl Ed). 2019;70(1):16-24. https://doi.org/10.1016/j.otorri.2017.10.005. Novel pathways involved in the cancerogenesis of sinonasal squamous cell carcinoma and potential therapeutic target.

14. Riobello C, Vivanco B, Reda S, et al. Programmed death ligand-1 expression as immunotherapeutic target in sinonasal cancer. Head Neck. 2018;40(4):818-27. https://doi.org/10.1002/ hed.25067.

15. Wang X, Lv W, Qi F, et al. Clinical effects of p53 overexpression in squamous cell carcinoma of the sinonasal tract: a systematic meta-analysis with PRISMA guidelines. Medicine (Baltimore). 2017;96(12):e6424. https://doi.org/10.1097/MD.0000000000 006424.

16. Li L, Zhu L. Expression and clinical significance of TrkB in sinonasal squamous cell carcinoma: a pilot study. Int J Oral Maxillofac Surg. 2017;46(2):144-50. https://doi.org/10.1016/j.ijom. 2016.09.027.

17. Leivo I. Sinonasal adenocarcinoma: update on classification, immunophenotype and molecular features. Head Neck Pathol. 2016;10(1):68-74. https://doi.org/10.1007/s12105-016-0694-9.

18. Bonzini M, Battaglia P, Parassoni D, et al. Prevalence of occupational hazards in patients with different types of epithelial sinonasal cancers. Rhinology. 2013;51(1):31-6. https://doi.org/ 10.4193/Rhino11.228.

19. Rampinelli V, Ferrari M, Nicolai P. Intestinal-type adenocarcinoma of the sinonasal tract: an update. Curr Opin Otolaryngol Head Neck Surg. 2018;26(2):115-21. https://doi.org/10.1097/ MOO.0000000000000445.
20. Barnes L. Intestinal-type adenocarcinoma of the nasal cavity and paranasal sinuses. Am J Surg Pathol. 1986;10(3):192-202. https://doi.org/10.1097/00000478-198603000-00006.

21. Kleinsasser O, Schroeder HG. The pathology and clinical picture of adenocarcinoma of the nose after wood dust exposure. Strahlenther Onkol. 1989;165(6):437-40.

22. Lechner M, Liu J, Lund VJ. Novel Biomarkers in sinonasal cancers: from bench to bedside. Curr Oncol Rep. 2020;22(10):106 https://doi.org/10.1007/s11912-020-00947-2.

23•. Hermsen MA, Riobello C, García-Marín R, et al. Translational genomics of sinonasal cancers. Semin Cancer Biol. 2020;61:101-9. https://doi.org/10.1016/j.semcancer.2019. 09.016. This is an impressive review of recent advances in genomics for sinonasal cancers, useful to have an overview on this topic.

24. Sánchez-Fernández P, Riobello C, Costales M, et al. Next-generation sequencing for identification of actionable gene mutations in intestinal-type sinonasal adenocarcinoma. Sci Rep. 2021;11(1):2247. https://doi.org/10.1038/s41598-020-80242-z.

25. Hoeben A, van de Winkel L, Hoebers F, et al. Intestinal-type sinonasal adenocarcinomas: the road to molecular diagnosis and personalized treatment. Head Neck. 2016;38(10):1564-70. https://doi.org/10.1002/hed.24416.

26. Costales M, López-Hernández A, García-Inclán C, et al. Gene methylation profiling in sinonasal adenocarcinoma and squamous cell carcinoma. Otolaryngol Head Neck Surg. 2016;155(5):808-15. https://doi.org/10.1177/0194599816 654139 .

27. Tomasetti M, Re M, Monaco F, et al. MiR-126 in intestinaltype sinonasal adenocarcinomas: exosomal transfer of MiR-126 promotes anti-tumour responses. BMC Cancer. 2018;18(1):896. https://doi.org/10.1186/s12885-018-4801-z.

28. Licitra L, Suardi S, Bossi P, et al. Prediction of TP53 status for primary cisplatin, fluorouracil, and leucovorin chemotherapy in ethmoid sinus intestinal-type adenocarcinoma. J Clin Oncol. 2004;22(24):4901-6. https://doi.org/10.1200/JCO.2004.05.071.

29. Gallet P, Nguyen DT, Russel A, et al. Intestinal and non-intestinal nasal cavity adenocarcinoma: Impact of wood dust exposure. Eur Ann Otorhinolaryngol Head Neck Dis. 2018;135(6):383-7. https://doi.org/10.1016/j.anorl.2018.08.012.

30. Bhaijee F, Carron J, Bell D. Low-grade nonintestinal sinonasal adenocarcinoma: a diagnosis of exclusion. Ann Diagn Pathol. 2011;15(3):181-4. https://doi.org/10.1016/j.anndiagpath.2010. 10.002 .

31. Skalova A, Sar A, Laco J, et al. The role of SATB2 as a diagnostic marker of sinonasal intestinal-type adenocarcinoma. Appl Immunohistochem Mol Morphol. 2018;26(2):140-6. https://doi. org/10.1097/PAI.0000000000000388.

32. Micheloni G, Millefanti G, Conti A, et al. Identification of OTX1 and OTX2 as two possible molecular markers for sinonasal carcinomas and olfactory neuroblastomas. J Vis Exp. 2019:(144). https://doi.org/10.3791/56880.

33. Pirrone C, Chiaravalli AM, Marando A, et al. OTX1 and OTX2 as possible molecular markers of sinonasal carcinomas and olfactory neuroblastomas. Eur J Histochem. 2017;61(1):2730. https://doi.org/10.4081/ejh.2017.2730.

34. Kubik M, Barasch N, Choby G, et al. Sinonasal renal celllike carcinoma: case report and review of the literature. Head Neck Pathol. 2017;11(3):333-7. https://doi.org/10.1007/ s12105-016-0774-x.

35. Yom SS, Rashid A, Rosenthal DI, et al. Genetic analysis of sinonasal adenocarcinoma phenotypes: distinct alterations of histogenetic significance. Mod Pathol. 2005;18(3):315-9. https:// doi.org/10.1038/modpathol.3800315.

36 Villatoro TM, Mardekian SK. Two cases of sinonasal nonintestinal-type adenocarcinoma with squamoid morules 
expressing nuclear $\beta$-catenin and CDX2: a curious morphologic finding supported by molecular analysis. Case Rep Pathol. 2018;2018:8741017. https://doi.org/10.1155/2018/8741017.

37 Skalova A, Cardesa A, Leivo I, et al. Sinonasal tubulopapillary low-grade adenocarcinoma. Histopathological, immunohistochemical and ultrastructural features of poorly recognised entity. Virchows Arch. 2003;443(2):152-8. https://doi.org/10. 1007/s00428-003-0844-9.

38. Andreasen S, Skálová A, Agaimy A, et al. ETV6 gene rearrangements characterize a morphologically distinct subset of sinonasal low-grade non-intestinal-type adenocarcinoma: a novel translocation-associated carcinoma restricted to the sinonasal tract. Am J Surg Pathol. 2017;41(11):1552-60. https://doi.org/ 10.1097/PAS.0000000000000912.

39. Andreasen S, Kiss K, Melchior LC, Laco J. The ETV6-RET gene fusion is found in etv6-rearranged low-grade sinonasal adenocarcinoma without NTRK3 involvement. Am J Surg Pathol. 2018;42(7):985-8. https://doi.org/10.1097/PAS.0000000000 001069.

40. Volpi L, Bignami M, Lepera D, et al. Endoscopic endonasal resection of adenoid cystic carcinoma of the sinonasal tract and skull base. Laryngoscope. 2019;129(5):1071-7. https://doi.org/ 10.1002/lary.27485.

41 . Castelnuovo P, Turri-Zanoni M: Adenoid Cystic Carcinoma. In: Nicolai P, Bradley PJ, editors. Anterior Skull Base Tumors. Adv Otorhinolaryngol. Basel, Karger; 2020. This book chapter is useful to understand current trends in the management of adenoid cystic carcinoma of the sinonasal tract.

42. Perzin KH, Gullane P, Clairmont AC. Adenoid cystic carcinomas arising in salivary glands: a correlation of histologic features and clinical course. Cancer. 1978;42(1):265-82. https://doi.org/10. 1002/1097-0142(197807)42:1\%3c265:aid-cncr2820420141\% 3e3.0.co;2-z.

43. Szanto PA, Luna MA, Tortoledo ME, White RA. Histologic grading of adenoid cystic carcinoma of the salivary glands. Cancer. 1984;54(6):1062-9. https://doi.org/10.1002/10970142(19840915)54:6\%3c1062:aid-cncr2820540622\%3e3.0. co;2-e.

44. Bell D, Bell AH, Bondaruk J, et al. In-depth characterization of the salivary adenoid cystic carcinoma transcriptome with emphasis on dominant cell type. Cancer. 2016;122(10):1513-22. https://doi.org/10.1002/cncr.29959.

45. Hanna EY, Abdelmeguid ASA, Roberts D, et al. Cellular subtype may predict survival outcomes in salivary adenoid cystic carcinoma patients-a single-institution experience. Virchows Arch. 2018;472(3):505-12. https://doi.org/10.1007/ s00428-017-2248-2.

46. Thierauf J, Ramamurthy N, Jo VY, et al. Clinically integrated molecular diagnostics in adenoid cystic carcinoma. Oncologist. 2019;24(10):1356-67. https://doi.org/10.1634/theoncologist. 2018-0515.

47. Ferrarotto R, Heymach JV, Glisson BS. MYB-fusions and other potential actionable targets in adenoid cystic carcinoma. Curr Opin Oncol. 2016;28(3):195-200. https://doi.org/10.1097/CCO. 0000000000000280.

48. Ferrarotto R, Mitani Y, Diao L, et al. Activating NOTCH1 mutations define a distinct subgroup of patients with adenoid cystic carcinoma who have poor prognosis, propensity to bone and liver metastasis, and potential responsiveness to Notch1 inhibitors. J Clin Oncol. 2017;35(3):352-60. https://doi.org/10.1200/ JCO.2016.67.5264.

49. Ho AS, Kannan K, Roy DM, et al. The mutational landscape of adenoid cystic carcinoma. Nat Genet. 2013;45(7):791-8. https:// doi.org/10.1038/ng.2643.

50. Bhaijee F, Pepper DJ, Pitman KT, Bell D. New developments in the molecular pathogenesis of head and neck tumors: a review of tumor-specific fusion oncogenes in mucoepidermoid carcinoma, adenoid cystic carcinoma, and NUT midline carcinoma. Ann Diagn Pathol. 2011;15(1):69-77. https://doi.org/10.1016/j.anndi agpath.2010.12.001

51. Hämetoja H, Mäkitie A, Bäck L, et al. Matrix metalloproteinase-7, $-8,-9,-15$, and -25 in minor salivary gland adenoid cystic carcinoma. Pathol Res Pract. 2021;217:153293. https://doi.org/ 10.1016/j.prp.2020.153293.

52. Bishop JA, Ogawa T, Stelow EB, et al. Human papillomavirusrelated carcinoma with adenoid cystic-like features: a peculiar variant of head and neck cancer restricted to the sinonasal tract. Am J Surg Pathol. 2013;37(6):836-44. https://doi.org/10.1097/ PAS.0b013e31827b1cd6.

53. Bishop JA, Andreasen S, Hang JF, et al. HPV-related multiphenotypic sinonasal carcinoma: an expanded series of 49 cases of the tumor formerly known as HPV-related carcinoma with adenoid cystic carcinoma-like features. Am J Surg Pathol. 2017;41(12):1690-701. https://doi.org/10.1097/PAS.00000 00000000944.

54. Rupp NJ, Camenisch U, Seidl K, et al. HPV-related multiphenotypic sinonasal carcinoma: four cases that expand the morpho-molecular spectrum and include occupational data. Head Neck Pathol. 2020;14(3):623-9. https://doi.org/10.1007/ s12105-019-01079-1.

55. Chen CC, Yang SF. Human papillomavirus-related carcinoma with adenoid cystic-like features of the sinonasal tract (also known as human papillomavirus-related multiphenotypic sinonasal carcinoma). Arch Pathol Lab Med. 2019;143(11):1420-4. https://doi.org/10.5858/arpa.2018-0027-RS.

56. Hsieh MS, Lee YH, Jin YT, Huang WC. Strong SOX10 expression in human papillomavirus-related multiphenotypic sinonasal carcinoma: report of 6 new cases validated by high-risk human papillomavirus mRNA in situ hybridization test. Hum Pathol. 2018;82:264-72. https://doi.org/10.1016/j.humpath.2018.07. 026.

57. Shah AA, Oliai BR, Bishop JA. Consistent LEF-1 and MYB immunohistochemical expression in human papillomavirusrelated multiphenotypic sinonasal carcinoma: a potential diagnostic pitfall. Head Neck Pathol. 2019;13(2):220-4. https://doi. org/10.1007/s12105-018-0951-1.

58. Ward ML, Kernig M, Willson TJ. HPV-related multiphenotypic sinonasal carcinoma: a case report and literature review. Laryngoscope. 2021;131(1):106-10. https://doi.org/10.1002/lary. 28598.

59. Fosbøl MØ, Bilde A, Friborg J, et al. An uncommon case of pediatric esthesioneuroblastoma presenting as SIADH: 18FFDG PET/CT in staging and post-therapeutic assessment. Diagnostics (Basel). 2018;8(1):8. https://doi.org/10.3390/diagnostic s8010008.

60. Nakano T, Motoshita J, Sawada F, et al. Syndrome of inappropriate antidiuretic hormone secretion in a case of olfactory neuroblastoma without anti-diuretic hormone immunoreactivity: a case report and review of the literature. Auris Nasus Larynx. 2017;44(6):771-4. https://doi.org/10.1016/j.anl.2016.11.012.

61. Thompson LD. Small round blue cell tumors of the sinonasal tract: a differential diagnosis approach. Mod Pathol. 2017;30(s1):S1-26. https://doi.org/10.1038/modpathol.2016. 119.

62. Fiani B, Quadri SA, Cathel A, et al. Esthesioneuroblastoma: a comprehensive review of diagnosis, management, and current treatment options. World Neurosurg. 2019;126:194-211. https:// doi.org/10.1016/j.wneu.2019.03.014.

63. Goshtasbi K, Abiri A, Abouzari M, et al. Hyams grading as a predictor of metastasis and overall survival in esthesioneuroblastoma: a meta-analysis. Int Forum Allergy Rhinol. 2019;9(9):1054-62. https://doi.org/10.1002/alr.22373. 
64. Turri-Zanoni M, Maragliano R, Battaglia $\mathrm{P}$, et al. The clinicopathological spectrum of olfactory neuroblastoma and sinonasal neuroendocrine neoplasms: refinements in diagnostic criteria and impact of multimodal treatments on survival. Oral Oncol. 2017;74:21-9. https://doi.org/10.1016/j.oraloncology. 2017.09.010.

65. Capper D, Engel NW, Stichel D, et al. DNA methylationbased reclassification of olfactory neuroblastoma. Acta Neuropathol. 2018;136(2):255-71. https://doi.org/10.1007/ s00401-018-1854-7.

66. Bell D. Sinonasal neuroendocrine neoplasms: current challenges and advances in diagnosis and treatment, with a focus on olfactory neuroblastoma. Head Neck Pathol. 2018;12(1):22-30. https://doi.org/10.1007/s12105-018-0887-5.

67. Classe M, Yao H, Mouawad R, et al. Integrated multi-omic analysis of esthesioneuroblastomas identifies two subgroups linked to cell ontogeny. Cell Rep. 2018;25(3):811-821.e5. https://doi. org/10.1016/j.celrep.2018.09.047.

68. Ivanidze J, Roytman M, Sasson A, et al. Molecular imaging and therapy of somatostatin receptor positive tumors. Clin Imaging. 2019;56:146-54. https://doi.org/10.1016/j.clinimag.2019.04.006.

69. Czapiewski P, Kunc M, Gorczyński A, et al. Frequent expression of somatostatin receptor $2 \mathrm{a}$ in olfactory neuroblastomas: a new and distinctive feature. Hum Pathol. 2018;79:144-50. https:// doi.org/10.1016/j.humpath.2018.05.013.

70. Gay LM, Kim S, Fedorchak K, et al. Comprehensive genomic profiling of esthesioneuroblastoma reveals additional treatment options. Oncologist. 2017;22(7):834-42. https://doi.org/10. 1634/theoncologist.2016-0287.

71 Czapiewski P, Kunc M, Haybaeck J. Genetic and molecular alterations in olfactory neuroblastoma: implications for pathogenesis, prognosis and treatment. Oncotarget. 2016;7(32):52584-96. https://doi.org/10.18632/oncotarget.9683.

72. Gallia GL, Zhang M, Ning Y, et al. Genomic analysis identifies frequent deletions of dystrophin in olfactory neuroblastoma. Nat Commun. 2018;9(1):5410. https://doi.org/10.1038/ s41467-018-07578-z.

73. de la Vega LL, McHugh JB, Cani AK, et al. Comprehensive molecular profiling of olfactory neuroblastoma identifies potentially targetable FGFR3 amplifications. Mol Cancer Res. 2017;15(11):1551-7. https://doi.org/10.1158/1541-7786. MCR-17-0135.

74. Topcagic J, Feldman R, Ghazalpour A, et al. Comprehensive molecular profiling of advanced/metastatic olfactory neuroblastomas. PLoS ONE. 2018;13(1):e0191244. https://doi.org/ 10.1371/journal.pone.0191244.

75. Turri-Zanoni M, Medicina D, Lombardi D, et al. Sinonasal mucosal melanoma: molecular profile and therapeutic implications from a series of 32 cases. Head Neck. 2013;35(8):1066-77. https://doi.org/10.1002/hed.23079.

76. Sayed Z, Migliacci JC, Cracchiolo JR, et al. Association of surgical approach and margin status with oncologic outcomes following gross total resection for sinonasal melanoma. JAMA Otolaryngol Head Neck Surg. 2017;143(12):1220-7. https://doi. org/10.1001/jamaoto.2017.2011.

77. Hur K, Zhang P, Yu A, et al. Open versus endoscopic approach for sinonasal melanoma: a systematic review and meta-analysis. Am J Rhinol Allergy. 2019;33(2):162-9. https://doi.org/10.1177/ 1945892418822637.

78. Boumahdi S, de Sauvage FJ. The great escape: tumour cell plasticity in resistance to targeted therapy. Nat Rev Drug Discov. 2020;19(1):39-56. https://doi.org/10.1038/s41573-019-0044-1.

79. Amit M, Abdelmeguid AS, Watcherporn T, et al. Induction chemotherapy response as a guide for treatment optimization in sinonasal undifferentiated carcinoma. J Clin Oncol. 2019;37(6):504-12. https://doi.org/10.1200/JCO.18.00353.
80. Bossi P, Farina D, Gatta G, et al. Paranasal sinus cancer. Crit Rev Oncol Hematol. 2016;98:45-61. https://doi.org/10.1016/j. critrevonc.2015.09.009.

81. Singh L, Ranjan R, Arava S, Singh MK. Role of p40 and cytokeratin $5 / 6$ in the differential diagnosis of sinonasal undifferentiated carcinoma. Ann Diagn Pathol. 2014;18(5):261-5. https://doi.org/10.1016/j.anndiagpath.2014.01.003.

82. Takahashi Y, Gleber-Netto FO, Bell D, et al. Identification of novel diagnostic markers for sinonasal undifferentiated carcinoma. Head Neck. 2019;41(8):2688-95. https://doi.org/10.1002/ hed.25748.

83. Qiang YY, Li CZ, Sun R, et al. Along with its favorable prognostic role, CLCA2 inhibits growth and metastasis of nasopharyngeal carcinoma cells via inhibition of FAK/ERK signaling. $\mathbf{J}$ Exp Clin Cancer Res. 2018;37(1):34. https://doi.org/10.1186/ s13046-018-0692-8.

84. Sasaki Y, Koyama R, Maruyama R, et al. CLCA2, a target of the p53 family, negatively regulates cancer cell migration and invasion. Cancer Biol Ther. 2012;13(14):1512-21. https://doi. org/10.4161/cbt.22280.

85. Agaimy A, Franchi A, Lund VJ, et al. Sinonasal undifferentiated carcinoma (SNUC): from an entity to morphologic pattern and back again-a historical perspective. Adv Anat Pathol. 2020;27(2):51-60. https://doi.org/10.1097/PAP.0000000000 000258 .

86. Jo VY, Chau NG, Hornick JL, et al. Recurrent IDH2 R172X mutations in sinonasal undifferentiated carcinoma. Mod Pathol. 2017;30(5):650-9. https://doi.org/10.1038/modpathol. 2016.239.

87. Guilmette J, Sadow PM. High-grade sinonasal carcinoma: classification through molecular profiling. Arch Pathol Lab Med. 2019;143(11):1416-9. https://doi.org/10.5858/arpa. 2018-0224-RS.

88. Dogan S, Vasudevaraja V, Xu B, et al. DNA methylationbased classification of sinonasal undifferentiated carcinoma. Mod Pathol. 2019;32(10):1447-59. https://doi.org/10.1038/ s41379-019-0285-x.

89. Bishop JA, Antonescu CR, Westra WH. SMARCB1 (INI1)-deficient carcinomas of the sinonasal tract. Am J Surg Pathol. 2014;38(9):1282-9. https://doi.org/10.1097/PAS.0000000000 000285 .

90. Dogan S, Cotzia P, Ptashkin RN, et al. Genetic basis of SMARCB1 protein loss in 22 sinonasal carcinomas. Hum Pathol. 2020;104:105-16. https://doi.org/10.1016/j.humpath. 2020.08.004.

91. Laco J, Chmelařová M, Vošmiková H, et al. SMARCB1/INI1deficient sinonasal carcinoma shows methylation of RASSF1 gene: a clinicopathological, immunohistochemical and molecular genetic study of a recently described entity. Pathol Res Pract. 2017;213(2):133-42. https://doi.org/10.1016/j.prp. 2016.10.012.

92. Shah AA, Jain D, Ababneh E, et al. SMARCB1 (INI-1)-deficient adenocarcinoma of the sinonasal tract: a potentially under-recognized form of sinonasal adenocarcinoma with occasional yolk sac tumor-like features. Head Neck Pathol. 2020;14(2):465-72. https://doi.org/10.1007/s12105-019-01065-7.

93. Agaimy A, Hartmann A, Antonescu CR, et al. SMARCB1 (INI1)-deficient sinonasal carcinoma: a series of 39 cases expanding the morphologic and clinicopathologic spectrum of a recently described entity. Am J Surg Pathol. 2017;41(4):458-71. https:// doi.org/10.1097/PAS.0000000000000797.

94. Agaimy A, Jain D, Uddin N, et al. SMARCA4-deficient sinonasal carcinoma: a series of 10 cases expanding the genetic spectrum of SWI/SNF-driven sinonasal malignancies. Am J Surg Pathol. 2020;44(5):703-10. https://doi.org/10.1097/PAS.00000 00000001428 . 
95. Rooper LM, Uddin N, Gagan J, et al. Recurrent loss of SMARCA4 in sinonasal teratocarcinosarcoma. Am J Surg Pathol. 2020;44(10):1331-9. https://doi.org/10.1097/PAS.00000 00000001508.

96. Xue Y, Meehan B, Fu Z, et al. SMARCA4 loss is synthetic lethal with CDK4/6 inhibition in non-small cell lung cancer. Nat Commun. 2019;10(1):557. https://doi.org/10.1038/ s41467-019-08380-1.

97. Shorstova T, Marques M, Su J, Johnston J, Kleinman CL, Hamel N, Huang S, Alaoui-Jamali MA, Foulkes WD, Witcher M. SWI/ SNF-compromised cancers are susceptible to bromodomain inhibitors. Cancer Res. 2019;79(10):2761-74. https://doi.org/ 10.1158/0008-5472.CAN-18-1545.

98 Chau NG, Ma C, Danga K, et al. An anatomical site and geneticbased prognostic model for patients with nuclear protein in testis (NUT) midline carcinoma: analysis of 124 patients. JNCI Cancer Spectr. 2019;4(2):pkz094. https://doi.org/10.1093/jncics/pkz094.

99 Vranic S, Caughron SK, Djuricic S, et al. Hamartomas, teratomas and teratocarcinosarcomas of the head and neck: Report of 3 new cases with clinico-pathologic correlation, cytogenetic analysis, and review of the literature. BMC Ear Nose Throat Disord. 2008. https://doi.org/10.1186/1472-6815-8-8.

100. Birkeland AC, Burgin SJ, Yanik M, et al. Pathogenetic analysis of sinonasal teratocarcinosarcomas reveal actionable $\beta$-catenin overexpression and a $\beta$-catenin mutation. J Neurol Surg B Skull Base. 2017;78(4):346-52. https://doi.org/10.1055/s-0037-16013 20.

101. Belardinilli F, De Vincentiis L, D'Ecclesia A, et al. PIK3CA somatic mutation in sinonasal teratocarcinosarcoma. Auris Nasus Larynx. 2021;48(3):530-4. https://doi.org/10.1016/j.anl. 2020.03.006

102••.Abdelmeguid AS, Bell D, Hanna EY. Neuroendocrine carcinoma and sinonasal undifferentiated carcinoma. Adv Otorhinolaryngol. 2020;84:168-84. https://doi.org/10.1159/00045 7936. This review is focused on poorly differentiated sinonasal cancers, analyzing both histopathological features and treatment options.

103. Rooper LM, Bishop JA, Westra WH. INSM1 is a sensitive and specific marker of neuroendocrine differentiation in head and neck tumors. Am J Surg Pathol. 2018;42(5):665-71. https://doi. org/10.1097/PAS.0000000000001037.

104. Kovarikova H, Bubancova I, Laco J, et al. Deregulation of selected microRNAs in sinonasal carcinoma: value of miR-21 as prognostic biomarker in sinonasal squamous cell carcinoma. Head Neck. 2017;39(12):2528-36. https://doi.org/10.1002/hed.24930.

105. La Rosa S, Sessa F, Uccella S. Mixed neuroendocrine-nonneuroendocrine neoplasms (MiNENs): unifying the concept of a heterogeneous group of neoplasms. Endocr Pathol. 2016;27(4):284311. https://doi.org/10.1007/s12022-016-9432-9.

106. Purgina B, Lai CK. Distinctive head and neck bone and soft tissue neoplasms. Surg Pathol Clin. 2017;10(1):223-79. https:// doi.org/10.1016/j.path.2016.11.003.

107. Nakayama R, Miura Y, Ogino J, et al. Detection of HEY1NCOA2 fusion by fluorescence in-situ hybridization in formalinfixed paraffin-embedded tissues as a possible diagnostic tool for mesenchymal chondrosarcoma. Pathol Int. 2012;62(12):823-6. https://doi.org/10.1111/pin.12022.

108. Simons SA, Bridge JA, Leon ME. Sinonasal small round blue cell tumors: an approach to diagnosis. Semin Diagn Pathol. 2016;33(2):91-103. https://doi.org/10.1053/j.semdp.2015.09.010.
109. Almomen A, Aldandan A, Alazzeh G, Alkhatib A. Ewing's sarcoma of the sinonasal tract: a report of two challenging cases. Indian J Otolaryngol Head Neck Surg. 2019;71(3):1849-53. https://doi.org/10.1007/s12070-018-01576-9.

110. Schaefer IM, Hornick JL. Diagnostic immunohistochemistry for soft tissue and bone tumors: an update. Adv Anat Pathol. 2018;25(6):400-12. https://doi.org/10.1097/PAP.0000000000 000204.

111. McCuiston A, Bishop JA. Usefulness of NKX2.2 immunohistochemistry for distinguishing Ewing sarcoma from other sinonasal small round blue cell tumors. Head Neck Pathol. 2018;12(1):89-94. https://doi.org/10.1007/s12105-017-0830-1.

112. Rooper LM, Bishop JA. Soft tissue special issue: adamantinomalike Ewing sarcoma of the head and neck: a practical review of a challenging emerging entity. Head Neck Pathol. 2020;14(1):5969. https://doi.org/10.1007/s12105-019-01098-y.

113. Le Loarer F, Cleven AHG, Bouvier C, et al. A subset of epithelioid and spindle cell rhabdomyosarcomas is associated with TFCP2 fusions and common ALK upregulation. Mod Pathol. 2020;33(3):404-19. https://doi.org/10.1038/s41379-019-0323-8.

$114 \mathrm{Xu}$ B, Suurmeijer AJH, Agaram NP, et al. Head and neck rhabdomyosarcoma with TFCP2 fusions and ALK overexpression: a clinicopathological and molecular analysis of 11 cases. Histopathology. 2020. https://doi.org/10.1111/his.14323.10.1111/his. 14323.

115. Lewis JT, Oliveira AM, Nascimento AG, et al. Low-grade sinonasal sarcoma with neural and myogenic features: a clinicopathologic analysis of 28 cases. Am J Surg Pathol. 2012;36(4):51725. https://doi.org/10.1097/PAS.0b013e3182426886.

116. Chitguppi C, Koszewski I, Collura K, et al. Biphenotypic sinonasal sarcoma-case report and review of clinicopathological features and diagnostic modalities. J Neurol Surg B Skull Base. 2019;80(1):51-8. https://doi.org/10.1055/s-0038-1667146.

117. Gross J, Fritchie K. Soft tissue special issue: biphenotypic sinonasal sarcoma: a review with emphasis on differential diagnosis. Head Neck Pathol. 2020;14(1):33-42. https://doi.org/10.1007/ s12105-019-01092-4.

118. Rooper LM, Huang SC, Antonescu CR, et al. Biphenotypic sinonasal sarcoma: an expanded immunoprofile including consistent nuclear $\beta$-catenin positivity and absence of SOX10 expression. Hum Pathol. 2016;55:44-50. https://doi.org/10. 1016/j.humpath.2016.04.009.

119. Wang X, Bledsoe KL, Graham RP, et al. Recurrent PAX3MAML3 fusion in biphenotypic sinonasal sarcoma. Nat Genet. 2014;46(7):666-8. https://doi.org/10.1038/ng.2989.

120. Ghaloo SK, Dhanani R, Pasha HA, et al. Glomangiopericytoma: a rare tumour of sinonasal cavity. J Pak Med Assoc. 2020;70(12(B)):2469-71. https://doi.org/10.47391/JPMA.948.

121 Kono M, Bandoh N, Matsuoka R, et al. Glomangiopericytoma of the nasal cavity with CTNNB1 p.S37C mutation: a case report and literature review. Head Neck Pathol. 2019;13(3):298-303. https://doi.org/10.1007/s12105-018-0961-z.

122. Suzuki Y, Ichihara S, Kawasaki T, et al. $\beta$-catenin (CTNNB1) mutation and LEF1 expression in sinonasal glomangiopericytoma (sinonasal-type hemangiopericytoma). Virchows Arch. 2018;473(2):235-9. https://doi.org/10.1007/s00428-018-2370-9.

Publisher's Note Springer Nature remains neutral with regard to jurisdictional claims in published maps and institutional affiliations. 